\title{
Produksi Sabun Cuci Piring Sebagai Upaya Peningkatkan Efektivitas Dan Peluang Wirausaha
}

\author{
Rizka Amalia*, Vita Paramita, Heny Kusumayanti, Wahyuningsih, Maranatha Sembiring, \\ dan Dina Elvia Rani \\ Program Studi Teknik Kimia, Departemen Teknologi Industri, Sekolah Vokasi, Universitas Diponegoro \\ Jl. Prof. Soedarto, Tembalang, Kota Semarang, Jawa Tengah 50275, Indonesia \\ Email: riz.chemicalia@gmail.com
}

\begin{abstract}
Abstrak
Sabun cuci piring merupakan salah satu kebutuhan dalam rumah tangga yang berfungsi sebagai penghilang kotoran dan lemak pada peralatan makan dan masak. Konsumsi sabun cuci piring yang terus menerus setiap harinya, menyebabkan kebutuhan pengadaan sabun dengan biaya yang tidak sedikit. Tujuan dilaksanakannya kegiatan kewirausahaan adalah untuk memberi pengetahuan dan pelatihan tentang pembuatan sabun cuci piring cair guna mengurangi pengeluaran masyarakat terhadap pembelian sabun sekaligus untuk menciptakan peluang usaha baru. Dalam kegiatan pengabdian, akan dijelaskan bahan baku, prosedur kerja dan perhitungan biaya produksi pembuatan sabun cuci piring. Dari kegiatan yang dilakukan, dapat menghasilkan luaran produk barang berupa sabun cuci piring cair sesuai dengan metode yang diberikan dalam pelatihan.
\end{abstract}

Kata kunci: sabun cuci piring, pelatihan, Pedalangan, Banyumanik

\section{Abstract \\ Production of Dish Washer Soap as Efforts to Increase Effectiveness And Entrepreneurial Opportunity}

Dishwashing liquid is one of household stuff that used for removing grease and dirt from dishes. Using the dishwashing liquid continuously cause the need of its stuff at a high enough cost. The purpose of this activity is to provide knowledge and training to the making of dishwashing liquid soap in order to reduce cost as well as to create new business opportunity. In this activities, the raw materials and procedure of producing dishwashing liquid will explained, and the production costs of dishwashing manufacture will calculated. From the activities undertaken, can produce the dishwashing liquid soap in accordance with the methods given in the training.

Keywords: dishwashing liquid, training, Pedalangan, Banyumanik

\section{PENDAHULUAN}

Sabun adalah bahan yang digunakan untuk mencuci, baik pakaian, perabotan, badan, dan lain-lain yang terbuat dari campuran alkali (natrium atau kalium hidroksida), dan trigliserida dari asam lemak rantai karbon $C_{16}$ (Zulkifli dan Estiasih, 2014) melalui reaksi saponifikasi atau disebut juga reaksi penyabunan pada suhu 80$100^{\circ} \mathrm{C}$ (Jongko, 2009). Dalam proses ini asam lemak akan terhidrolisa oleh basa membentuk gliserin dan sabun mentah.

Sabun dapat menghilangkan kotoran dan minyak karena struktur kimia sabun terdiri dari bagian yang bersifat hidrofil pada rantai ionnya, dan bersifat hidrofobik pada rantai karbonnya. Karena adanya rantai hidrokarbon, sebuah molekul sabun secara keseluruhan tidaklah benar-benar larut dalam air. Namun sabun mudah tersuspensi dalam air karena membentuk misel 
(micelles), yakni segerombolan (50-150) molekul yang rantai hidrokarbonnya mengelompok dengan ujung- ujung ionnya yang menghadap ke air (Fessenden dan Fessenden, 1992). Dalam menghilangkan kotoran dan minyak, bagian yang bersifat hidrofobik pada sabun akan larut dalam minyak dan mengepung kotoran minyak, sedangkan bagian hidrofilik akan terlepas dari permukaan yang dibersihkan dan terdispersi dalam air sehingga dapat dicuci (Djatmiko dan Widjaja, 1984).

Sabun sebagai salah satu kebutuhan utama untuk mendapatkan standar kebersihan yang baik dalam kehidupan sehari-hari termasuk dalam kebutuhan pokok, tetapi sabun tidak termasuk dalam kelompok kebutuhan primer. Pemenuhan akan sabun seringkali dianggap sebagai kebutuhan sekunder, karena kebutuhan primer (sandang, pangan, papan) merupakan kebutuhan yang wajib untuk dipenuhi setiap hari. Konsumsi sabun yang terus menerus setiap harinya, menyebabkan kebutuhan pengadaan sabun yang membutuhkan biaya yang tidak sedikit.

Dalam menjalankan usaha pembuatan jajan sederhana, sabun yang selama ini digunakan untuk mencuci piring adalah sabun colek dengan harga $\mathrm{Rp} 2.600,-$ per sachet per hari. Penyediaan sabun sachet untuk 1 bulan membutuhkan biaya sebanyak Rp 52.000,- Hal ini menunjukkan bahwa masyarakat harus menyediakan dana minimal Rp 52.000,- per bulan untuk pengadaan sabun yang diperlukan untuk membersihkan peralatan memasak.

Tujuan kegiatan kewirausahaan adalah untuk memberikan pengetahuan dan pelatihan tentang pembuatan sabun cuci piring cair sekaligus untuk membantu mengurangi pengeluaran masyarakat untuk pembelian sabun dengan harga yang mahal. Produksi sabun cuci piring secara massal juga dapat menciptakan peluang usaha baru.

\section{METODOLOG}

Kegiatan pengabdian masyarakat meliputi identifikasi permasalahan yang muncul pada masyarakat sesuai dengan kompetensi masyarakat bersangkutan. Permasalahan tersebut yang selanjutnya dikaji dan dicarikan solusi. Metode pendekatan untuk dapat menyelesaikan permasalahan dalam kegiatan ini menggunakan metode Participatory Action Research (PAR). Solusi yang ditawarkan pada kegiatan kewirausahaan pada masyarakat ini berupa pemberian penyuluhan dengan materi yang telah ditentukan.

Bahan-bahan pembuatan sabun dapat dengan mudah ditemukan di toko kimia terdekat. Bahan dasar pembuatan sabun cair meliputi SLS, texapon dan garam serta bahan aditif seperti parfum, pengawet, pengental dan zat pewarna.

\section{HASIL DAN PEMBAHASAN}

Kewirausahaan adalah suatu kemampuan untuk mengelola sesuatu yang ada di dalam diri seseorang untuk dimanfaatkan dan ditingkatkan agar lebih optimal (baik) sehingga bias meningkatkan taraf hidup di masa mendatang (Meredith, 2002). Menurut Aprijon (2013) salah satu faktor pendorong pertumbuhan kewirausahaan disuatu negara terletak pada peranan universitas melalui penyelenggaraan

Tabel 1. Bahan baku pembuatan sabun cuci piring

\begin{tabular}{llrl}
\hline \multicolumn{1}{c}{ Bahan } & \multicolumn{1}{c}{ Fungsi } & Kuantitas & Satuan \\
\hline HEC (Hydroxy Ethyl Cellulose) & Pengental & 2 & $\mathrm{gr}$ \\
Texapon 70 & pengangkat kotoran dan penghasil busa & 125 & $\mathrm{gr}$ \\
$\mathrm{NaCl}$ & Pengental, pencampur sabun & $20 \mathrm{gr}$ \\
Asam sitrat & Pengawet, pengangkat lemak & $2 \mathrm{gr}$ \\
Sodium benzoat & Pengawet & $2 \mathrm{gr}$ \\
Sanisol & Desinfektan & $2 \mathrm{cc}$ \\
Pewarna (merah) & (larutkan 1 gr pewarna dalam 100 cc air) & 5 tetes \\
Air & Pelarut & $820 \mathrm{cc}$ \\
Tergitol NPX & zat pembantu & $20 \mathrm{cc}$ \\
\hline
\end{tabular}


pendidikan kewirausahaan. Oleh karena itu, perlu dibina kepribadian individu yang sangat mempengaruhi keberhasilan usaha. Dengan memiliki jiwa pemimpin, siap mental untuk menghadapi segala resiko dan tantangan dalam hidupnya.

Melalui penerapan teknologi tepat guna yang sederhana dalam pelatihan ini, diharapkan dapat diperoleh pemberdayaan masyarakat dengan peningkatan keterampilan yang bermanfaat. Teknologi sederhana ini dapat diterapkan oleh masyarakat secara umum. Teknologi ini juga diharapkan menjadi pemicu tumbuhnya semangat kewirausahaan yang lain untuk setidaknya mencukupi kebutuhan sabun cuci piring.

Keahlian masyarakat sesudah adanya transfer metode pembuatan sabun cair diharapkan: (i) mampu membuat sabun cair yang disertai dengan pemahaman dasar akan sabun; (ii) mampu mengatur (me-manage) efisiensi maupun efektifitas penggunaan sabun cair agar tidak boros dalam pemakaiannya; (iii) mampu mengkoordinasikan sistem/cara pembuatan sabun di lingkungan RT; (iv) mampu menjadikan sabun sebagai terobosan untuk memperoleh tambahan uang keluarga; (v) mampu menghitung keuntungan yang dapat diperoleh dengan memanfaatkan peluang wirausaha. Dari kegiatan yang dilakukan, masyarakat memperoleh luaran produk barang, berupa sabun cuci piring cair secara mandiri untuk kapasitas 1 liter, yang dihasilkan sesuai dengan metode yang ditawarkan (Gambar 1).

\section{Proses Pembuatan Sabun Cuci Piring}

Sabun adalah surfaktan yang digunakan dengan air untuk mencuci dan membersihkan. Untuk keperluan mencuci piring dan peralatan masak lainnya, kegunaan sabun cair telah meluas (Apriyani, 2013) dan banyak dipilih masyarakat dibandingkan sabun batangan dan sabun colek. Keunggulan sabun cair yakni lebih higenis karena biasanya disimpan dalam wadah yang tertutup rapat (Wijana et al, 2009).

Pembuatan sabun dengan tahapan dan takaran yang benar akan menghasilkan sabun cair yang berkualitas. Ada 2 tahapan yang dilakukan (Tanjung, 2017), tahapan yang pertama adalah :

a. Tahapan pembuatan bahan dasar sabun.

- Larutan A dibuat dengan mencampurkan $125 \mathrm{~g}$ Texapon, 20 cc Tergitol NPX, $20 \mathrm{~g}$ $\mathrm{NaCl}$ dan $2 \mathrm{~g}$ HEC dalam satu wadah (ember) dan disi dengan air sebanyak 200 cc. Diaduk sampai kedua bahan tersebut larut dengan air.

- Larutan B dibuat dengan melarutkan $2 \mathrm{~g}$ sodium benzoate, 2 gasam sitrat dan 2 cc sanisol dalam $650 \mathrm{cc}$ air dalam ember.

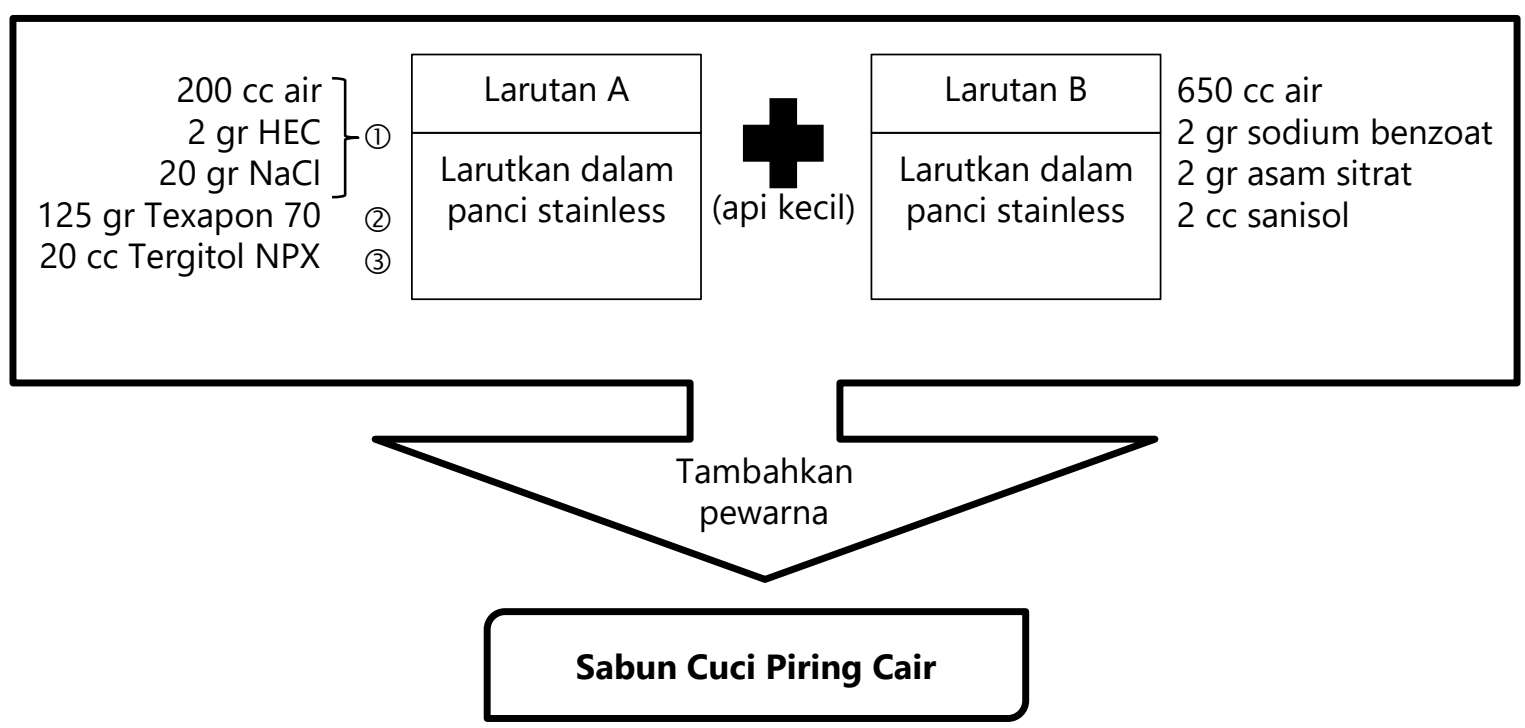

Gambar 1. Diagram alir pembuatan sabun cuci piring kapasitas 1 liter 
Tabel 2. Peluang penjualan dan keuntungan dalam satu kali produk

\begin{tabular}{ccccc}
\hline Modal $(\mathrm{Rp})$ & Total Produksi & Harga jual/liter (Rp) & Total penjualan (Rp) & Keuntungan (Rp) \\
\hline Rp. 15.000 & 1 liter & Rp. 21.500 & Rp. 21.500 & Rp. 6.500 \\
\hline
\end{tabular}

b. Tahapan penambahan zat aditif.

- Zat Pengawet. Penambahan zat pengawet adalah untuk menekan hidup mikroorganisme yang dibawa oleh air yang tidak steril.

- Parfum, Dosis parfum dapat disesuaikan dengan banyaknya jumlah sabun yang dihasilkan yaitu sebanyak $15 \mathrm{ml}$.

- Zat pewarna, digunakan untuk membuat produk lebih menarik (Utami, 2009). Kepekatan warna juga dapat disesuaikan dengan selera dan warnanya harus disesuaikan dengan parfum. Penambahan zat aditif kedalam sabun diaduk sampai merata dan pembuatan sabun telah selesai dilakukan.

\section{Analisis Ekonomi Usaha Pembuatan Sabun Cuci Piring}

Harga satu pak bahan pembuat sabun dengan kapasitas 1 Liter adalah Rp 15.000,-. Keuntungan yang diperoleh dalam sekali memproduksi sebesar Rp. 50.000,- atau sekitar $43 \%$. Keuntungan tersebut belum termasuk biaya kemasan.

\section{KESIMPULAN}

Dalam pelatihan pembuatan sabun cuci piring dapat diambil kesimpulan bahwa kegiatan dapat berjalan dengan lancar sesuai dengan yang direncanakan. Kegiatan ini dapat meningkatkan pengetahuan dan ketrampilan dalam pembuatan sabun cuci piring yang dapat dikonsumsi pribadi maupun dikomersilkan.

\section{DAFTAR PUSTAKA}

Aprijon. 2013. Kewirausahaan dan Pandangan Islam. Menara. 12(1):1-11

Apriyani, D. 2013. Formulasi Sediaan Sabun Mandi Cair Minyak Atsiri Jeruk Nipis (Citrus aurantifolia) Dengan Cocamid Dea Sebagai Surfaktan. Universitas Muhammadiyah Surakarta (Doctoral dissertation)

Djatmiko, B. \& Widjaja, A.P. 1985. Teknologi Lemak dan Minyak Ikan. Bogor : Agro Industri Press. Fateta-IPB.

Fessenden, R. J. \& Fessenden, J. S. 1992. Kimia Organik, Jilid 2, Edisi ketiga. Penerbit Erlangga, Jakarta

Jongko. 2009. Sabun Kecantikan: Teori dan Praktek Membuat Sabun Beauty di Rumah. Jakarta : Duraposita Chemistry

Meredith, G. 2003. Kewirausahaan Teori dan Praktek. Jakarta : Pustaka Binaman Pressindo

Tanjung, D.A., 2017. Pelatihan Pembuatan Sabun Cair dan Shampoo Pencuci Mobil. Jurnal Prodikmas Hasil Pengabdian Masyarakat. 2(1):41-45.

Utami, W.P. 2009. Proses Pembuatan Sabun Cair dari Minyak Goreng Bekas (Jelantah). Laporan Akhir. Palembang: Politeknik Sriwijaya.

Wijana, S., Sumarjo \& Harnawi, T., 2009. Studi pembuatan sabun mandi cair dari daur ulang minyak goreng bekas (Kajian pengaruh lama pengadukan dan rasio air: sabun terhadap kualitas). Jurnal Teknologi Pertanian, 10(1):54-61.

Zulkifli, M. \& Estiasih. 2014. Sabun dari Distilat Asam Lemak Minyak Sawit. Jurnal Pangan dan Agroindustri. 2 (4):170-177 